\title{
Pathogenesis of psoriasis in the "omic" era. Part III. Metabolic disorders, metabolomics, nutrigenomics in psoriasis
}

\author{
Agnieszka Owczarczyk-Saczonek ${ }^{1}$, Dorota Purzycka-Bohdan², Bogusław Nedoszytko², Adam Reich ${ }^{3}$, \\ Aneta Szczerkowska-Dobosz ${ }^{2}$, Joanna Bartosińska ${ }^{4}$, Aleksandra Batycka-Baran ${ }^{5}$, Rafał Czajkowski', Iwona T. Dobrucki ${ }^{7}$, \\ Lawrence W. Dobrucki ${ }^{7,8,9,10}$, Magdalena Górecka-Sokołowska ${ }^{5}$, Anna Janaszak-Jasiecka9 ${ }^{9}$, Leszek Kalinowski,11,12, \\ Dorota Krasowska ${ }^{4}$, Adrianna Radulska ${ }^{13}$, Edyta Reszka ${ }^{14}$, Dominik Samotij ${ }^{3}$, Andrzej Słominski ${ }^{15}$, Radomir Słominski ${ }^{16}$, \\ Marta Sobalska-Kwapis ${ }^{17}$, Marta Stawczyk-Macieja ${ }^{2}$, Dominik Strapagiel ${ }^{17}$, Justyna Szczęch ${ }^{3}$, Michał Żmijewski ${ }^{18}$, \\ Roman J. Nowicki
}

${ }^{1}$ Chair and Department of Dermatology, Sexually Transmitted Diseases and Clinical Immunology, Collegium Medicum, University of Warmia and Mazury, Olsztyn, Poland

${ }^{2}$ Chair and Department of Dermatology, Venereology and Allergology, Medical University of Gdansk, Gdansk, Poland

${ }^{3}$ Department of Dermatology, University of Rzeszow, Rzeszow, Poland

${ }^{4}$ Chair and Department of Dermatology, Venereology and Pediatric Dermatology, Medical University of Lublin, Lublin, Poland

${ }^{5}$ Chair and Department of Dermatology, Venereology and Allergology, Wroclaw Medical University, Wroclaw, Poland

${ }^{6}$ Chair and Department of Dermatology, Sexually Transmitted Diseases and Immunodermatology, Collegium Medicum in Bydgoszcz,

Nicolaus Copernicus University in Torun, Poland

${ }^{7}$ Beckman Institute for Advanced Science and Technology, Urbana, IL, USA

${ }^{8}$ Department of Bioengineering, University of Illinois at Urbana-Champaign, Urbana, IL, USA

${ }^{9}$ Department of Medical Laboratory Diagnostics, Medical University of Gdansk, Gdansk, Poland

${ }^{10}$ Biobanking and Biomolecular Resources Research Infrastructure Poland (BBMRI.PL), Gdansk, Poland

${ }^{11}$ Department of Molecular Genetics and Epigenetics, Nofer Institute of Occupational Medicine, Lodz, Poland

${ }^{12}$ Gdansk University of Technology, Gdansk, Poland

${ }^{13}$ Department of Pharmaceutical Biochemistry, Medical University of Gdansk, Gdansk, Poland

${ }^{14}$ Department of Molecular Genetics and Epigenetics, Nofer Institute of Occupational Medicine, Lodz, Poland

${ }^{15}$ Department of Dermatology, University of Alabama at Birmingham, Birmingham, USA

${ }^{16}$ Department of Medicine and Microbiology, Division of Clinical Immunology and Rheumatology, University of Alabama at Birmingham, Birmingham, USA

${ }^{17}$ Biobank Laboratory, University of Lodz, Lodz, Poland

${ }^{18}$ Department of Histology, Medical University of Gdansk, Gdansk, Poland

Adv Dermatol Allergol 2020; XXXVII (4): 452-467

DOI: https://doi.org/10.5114/ada.2020.98284

\begin{abstract}
Psoriasis is a systemic disease that is strictly connected with metabolic disorders (insulin resistance, atherogenic dyslipidemia, arterial hypertension, and cardiovascular diseases). It occurs more often in patients with a more severe course of the disease. Obesity is specially an independent risk factor and it is associated with a worse treatment outcome because of the high inflammatory activity of visceral fatty tissue and the production of inflammatory mediators involved in the development of both psoriasis and metabolic disorders. However, in psoriasis the activation of the Th17/IL-17 and the abnormalities in the Th17/Treg balance axis are observed, but this pathomechanism does not fully explain the frequent occurrence of metabolic disorders. Therefore, there is a need to look for better biomarkers in the diagnosis, prognosis and monitoring of concomitant disorders and therapeutic effects in psoriasis. In addition, the education on the use of a proper diet as a prophylaxis for the development of the above disorders is an important element of holistic care for a patient with psoriasis. Diet may affect gene expression due to epigenetic modification which encompasses interactions of environment, nutrition and diseases. Patients with psoriasis should be advised to adopt proper diet and dietician support.
\end{abstract}

Key words: psoriasis, inflammation, metabolic syndrome, metabolomics, proteomic nutrigenomics.

Address for correspondence: Agnieszka Owczarczyk-Saczonek MD, PhD, Chair and Department of Dermatology, Sexually Transmitted Diseases and Clinical Immunology, University of Warmia and Mazury, 30 Wojska Polskiego St, 10-229 Olsztyn, Poland, phone: +48 8967866 70, fax: +48 896786675 , e-mail: aganek@wp.pl

Received: 31.03.2020, accepted: 28.05.2020. 


\section{Introduction}

Psoriasis is a disease in which a complex pathomechanism is associated with the activation of Th17/IL-17 and abnormalities of Th17/Treg balance axis, which leads to abnormal proliferation of epidermal cells, inflammatory infiltration and vascular lesions in the dermis, and consequently the development of typical lesions [1, 2]. However, this mechanism does not fully explain the frequent occurrence of metabolic disorders (insulin resistance, atherogenic dyslipidemia, arterial hypertension, and cardiovascular diseases), especially in patients with a severe course of the disease [3, 4]. Therefore, there is a need to look for better biomarkers in the diagnosis, prognosis and to monitor concomitant disorders and therapeutic effects in this disease. In recent years, proteomics (systematic analysis of proteins in terms of their identity, quantity and function) has been developing [3].

\section{Metabolic disorders and the role of adipose tissue in induction of inflammation in psoriasis}

According to the International Diabetes Federation, metabolic syndrome (MS) is defined as the presence of three or more of the following features: abdominal obesity, hyperglycemia, hypertension, low high-density lipoprotein (HDL) cholesterol levels, and/or hypertriglyceridemia [5]. Obesity plays a critical role in the development of insulin resistance (IR) and type 2 diabetes (T2DM) and leads to many metabolic disorders such as dyslipidemia, non-alcoholic fatty liver disease (NAFLD), hypertension, coronary artery disease and stroke $[6,7]$. Literature review concerning morbidity and mortality due to psoriasis revealed an increased risk of myocardial infarction in psoriatic patients in comparison to general population - OR (odds ratio) $=1.25$. The risk was even higher in patients with more severe skin lesions and those with early onset of the disease. In addition, the risk of myocardial infarction was markedly higher in patients with psoriatic arthritis (PsA) $(O R=1.57)$ in comparison to patients with psoriasis $(O R=1.25)$. The risk of stroke in PsA, however, was only mildly elevated $(\mathrm{OR}=1.14)[8,9]$.

The correlation between obesity and psoriasis has been confirmed in many epidemiological studies. It is also believed that obesity is an independent risk factor for psoriasis and is associated with a worse outcome [10-12]. Obesity (body mass index (BMI) $>29 \mathrm{~kg} / \mathrm{m}^{2}$ ) increases the risk of psoriasis by almost 2 times [13]. In contrast, the reduction of body weight decreases the severity of psoriasis [13]. A study done in South Korea recruited more than 22.5 million subjects including 399461 patients with psoriasis reported that people with $\mathrm{BMI}>30 \mathrm{~kg} / \mathrm{m}^{2}$, similarly to those with waist circumference $>105 \mathrm{~cm}$, had a higher risk of psoriasis (hazard ratio $(H R)=1.118$ and 1.305 , respectively) [14]. The risk of psoriasis was highest in males with a normal BMI and abdominal obesity $(H R=1.175)$. This observation reflects the main role of abdominal obesity in the pathogenesis of psoriasis and concomitant diseases [14]. The meta-analysis of prospective studies has confirmed that increase in $\mathrm{BMI}$ and waist circumference leads to an increase in the risk of developing psoriasis by $19 \%$ and $24 \%$, respectively $[14,15]$. This close relationship, the similar pathomechanism of both processes, allowed the formulation of the theory of "psoriatic march". Inflammation associated with systemic disease, fanned by pro-inflammatory cytokines and adipokines produced by the visceral adipose tissue lead to the development of IR, and endothelial cell damage. Endothelial dysfunction predisposes to the formation of atherosclerotic plaques and faster development of cardiovascular events (Figure 1) $[11,16]$.

Patients with obesity and $\mathrm{HLA}-\mathrm{CW}^{*} \mathrm{O} 6$ gene were 35 times more likely to develop psoriasis when compared to individuals with normal weight and without that gene [17]. It has been observed that the rise of BMI increases the risk of PsA [18]. Some studies suggest however, that obesity may be the consequence of psoriasis rather than its risk factor [11, 19] (Figure 1).

\section{The role of adipose tissue in metabolic disorders}

The visceral adipose tissue's role is not only to store energy and to insulate body, but it is also regarded as an important neuro-immuno-endocrine organ that participates in homeostasis. The adipose tissue expands due

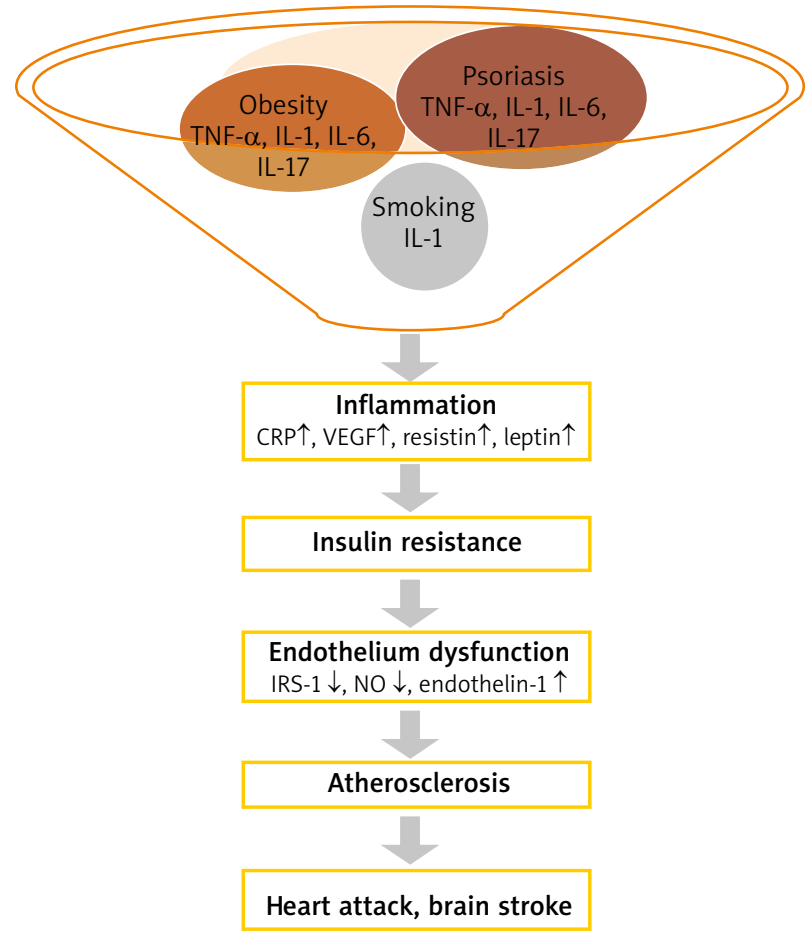

Figure 1. An overview of the mechanism behind the "psoriatic march" [16] 
to two mechanisms: cell size increase (hypertrophy) and cell number increase (hyperplasia). Initially, the excess of energy that is stored as fat protects against metabolic disorders associated with hyperglycemia. An excessive amount of adipose tissue and further caloric imbalance leads to lipotoxicity which results in an increase of adipose tissue volume not only in the subcutaneous and visceral compartments, but also in other organs (liver, skeletal muscles and heart). Moreover, lipotoxicity is closely linked to the development of inflammation and IR [6, 20-22]. In normal conditions, insulin reduces the glucose level by inducing glucose uptake in insulin-sensitive tissues (skeletal muscles, adipose tissue and liver) and reducing hepatic glucose production. IR occurs when insulin-sensitive tissues do not respond properly to insulin. As a result, excessive insulin production in pancreatic $\beta$-cells occurs. This leads to hyperinsulinemia - a metabolic state in which a reduction of insulin receptors in various cells (myocytes, hepatocytes and adipocytes) is observed. Moreover, these metabolic alterations further exacerbate IR, creating a vicious circle. It has also been observed that insulin secretion correlates with the amount of adipose tissue. Therefore, obese individuals produce more insulin than people with normal weight. Insulin hypersecretion counterbalances the IR. The function of cells that are sensitive to insulin remains preserved until insulin hypersecretion compensates IR. Excessive insulin concentration, however, acts also as an anabolic hormone and promotes accumulation of visceral adipose tissue $[8,23,24]$. It has also been shown recently that the amount of pericardial adipose tissue, which is a potent atherosclerosis risk factor, increases in patients with psoriasis. In addition, pericardial adipose tissue was found to contain macrophage infiltration and increased interleukin $1 \beta$ (IL-1 $\beta)$, IL-6, monocyte chemoattractant protein-1 (MCP-1) and tumor necrosis factor $\alpha$ (TNF- $\alpha$ ) secretion was observed [25].

\section{Activation of adipose tissue macrophages and psoriasis}

The number of macrophages in visceral adipose tissue was found to be greater than in subcutaneous adipose tissue in obese patients. As hyperinsulinemia and IR exacerbate, constantly expanding adipocytes start to secrete IL-6, IL-8, reactive oxygen species (ROS) and free fatty acids (FFA). This leads to bone marrow recruitment and secretion of macrophages which then turn to adipose tissue macrophages. These macrophages may constitute up to $60 \%$ of the adipose tissue mass [11, 26, 27]. Moreover, adipose tissue macrophages play an important role in the development of chronic inflammation in adipose tissue and exacerbate inflammatory state by promoting pro-inflammatory cytokines such as TNF- $\alpha$, IL-6, IL-8, IL-17, IL-18 and MCP-1, pro-inflammatory adipokines (resistin, visfatin, retinol binding protein-4) and inducible nitric oxide synthase (iNOS) production [11, 27,
28]. ROS induce the secretion of pro-inflammatory cytokines, expression of adhesive molecules and growth factors (e.g. connective tissue growth factor (CTGF), insulinlike growth factor (IGF-I), platelet-derived growth factor (PDGF) and vascular cell adhesion molecule-1 (VCAM-1)) [28]. Macrophages also produce components of reninangiotensin system and stimulate aldosterone release which may explain the development of hypertension in obese patients [29]. Other factors secreted by adipocytes and macrophages stimulate the formation of cell adhesion molecules such as ICAM-1, PECAM-1 [26]. Interestingly, the use of anti-TNF- $\alpha$ monoclonal antibodies has led to the reduction of inflammation in adipose tissue $[11,30]$. TNF- $\alpha$, IL-6 and IL-17 all play important roles in the development of inflammation in psoriasis and are not only locally distributed in skin lesions but affect the whole body. In addition, TNF- $\alpha$ contributes to IR due to inhibition of insulin receptor signaling, human glucose transporter 4 (GLUT-4), and insulin secretion in pancreatic $\beta$-cells and inhibition of anti-inflammatory adiponectin secretion in adipocytes which is an insulin sensitivity enhancing factor [11, 31]. Finally, IR directly leads to endothelial dysfunction and increases the risk of myocardial infarction and stroke, as in the "psoriatic march" theory $[11,27]$.

\section{The endocrine function of adipose tissue and psoriasis}

It has been shown that adipocytes secrete many paracrine factors known as adipokines which regulate metabolism [11, 16]. Moreover, these adipokines, mainly resistin and leptin, correlate with PASI but not with BMI in psoriatic patients (Figure 2). Their profile is similar to that of individuals with IR [16, 32]. Some studies reported that there was an alteration of adipokine secretion in obese individuals which was probably due to hypoxia of hypertrophic adipocytes [6]. Leptin plays a particular role as it rises in obesity and has an impact on pro-inflammatory cytokines expression, i.e. TNF- $\alpha$, IL-2, IL- 6 and MCP-1, all of which have prothrombotic properties [33]. It is also evident that the levels of protective adipokines: adiponectin and omentin is usually decreased in patients with severe course of psoriasis [34, 35]. On the other hand, increased levels of leptin, chemerin, visfatin, resistin and plasminogen activator inhibitor-1 (PAI-1) decreased after successfully treatment $[12,32,35,36]$. Moreover, an increased chemerin expression in a new-onset psoriatic lesion was strictly associated with activation of pDC, while in chronic psoriatic lesions was normal [37]. AntiTNF treatment resulted in normalization of chemerin and resistin serum levels [36]. The data on lipocalin-2 and retinol binding protein (RBP)-4 are conflicting and further studies are required [12]. In addition, the adipose tissue has the capability of producing proopiomelanocortin (POMC) derived peptides with anti-inflammatory activities and is involved in glucosteroidogenesis [38, 39]. 


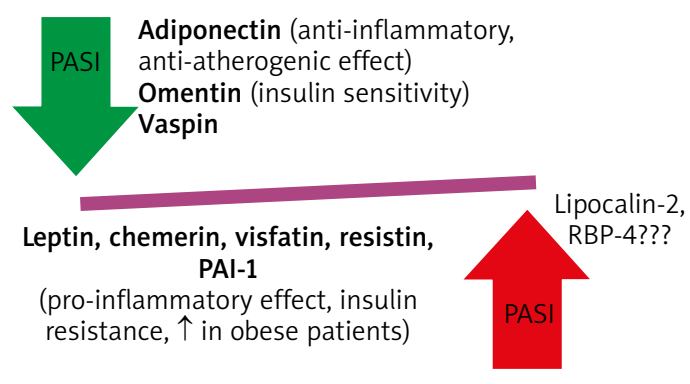

Figure 2. The role of adipokines in psoriasis

The adipocytes have large numbers of $\beta$-adrenergic and glucocorticoid receptors. Their stimulation leads to lipolysis of the stored triglycerides and secretion of free fatty acids (FFA) [40]. In addition, TNF- $\alpha$ and angiotensinogen produced by adipocytes inhibit the effects of insulin. It has also been shown that FFA have an important impact on metabolism. However, the strongest effect is exerted by FFA, which arise as a result of intracellular lipase and lipoprotein lipase, which degrade VLDL. These compounds circulate in plasma and are stored in organs [22]. The accumulation of FFA in liver leads to impaired insulin sensitivity which results in peripheral hyperinsulinemia and IR. Moreover, the increased level of FFA in liver is ultimately associated with atherogenic LDL production [41].

With the complex interplay between adipokines and pro-inflammatory cytokines the obesity may be characterized as a chronic inflammatory state of low grade with increased oxidative stress (OS). This leads to cell structure destruction, further apoptosis of adipocytes with lack of adequate antioxidative mechanisms and as a consequence - the development of complications related to obesity (Figure 3) [28].

\section{Visceral adipose tissue immune system and psoriasis}

Visceral adipose tissue is a source of pro-inflammatory cytokines which are similar to those secreted in psoriatic inflammation. Interleukin- 6 which is secreted by visceral adipose tissue macrophages, promotes the differentiation of naive T lymphocytes to Th17 [42, 43]. This is an example of a positive feedback mechanism due to the fact that IL-17 stimulates the production of IL-6 [11, 44]. Interleukin 17 which is a potent pro-inflammatory cytokine, is responsible for maintenance of inflammation in visceral adipose tissue and stimulates adipocyte lipolysis [4, 45]. However, it exerts a beneficial effect by inhibiting adipogenesis and adipocyte differentiation [4, 42]. Many studies suggested that Th17 and IL-17 may constitute a missing link between inflammation, autoimmune reaction and obesity [43]. Interestingly, in obese women the increased concentration

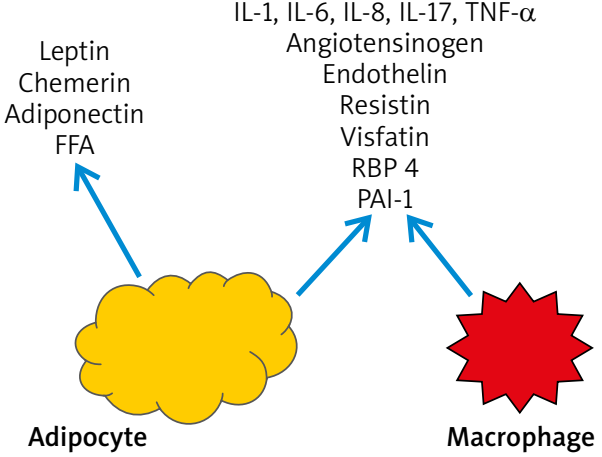

Figure 3. Visceral adipose tissue endocrine function [11, 32]

of IL-23 which stimulates Th17 and IL-17 was observed but without an increased level of Th1-related cytokines (IL-12, IFN- $\gamma$ ) [46]. In has been observed that during IL-17A signaling the level of intracellular total cholesterol is elevated, which results in cholesterol gene suppression and promotes fatty acids synthesis in keratinocytes. This mechanism may explain the strong correlation between psoriasis and dyslipidemia [47].

As in psoriasis, a reduced IL-10 concentration is also observed in MS, obesity, IR and T2DM circulating endothelial cells. Weight loss also leads to IL-10 increase in obese patients $[4,48]$.

Based on complex interdependence between adipokines, the obesity is characterized by chronic inflammation of low grade and increased OS. Consequently, the cell structure is more prone to damage due to endothelial dysfunction and lipid peroxidation (ox-LDL cholesterol is one of the major factors of atherosclerosis) which in combination with insufficient antioxidative mechanisms result in the development of obesity complications (hypertension, fatty liver disease, atherosclerosis) [7, 28]. Due to the fact that there is a strong correlation between OS, antioxidative function and metabolic disorders. Some experts postulate that OS is one the major factors in the MS pathogenesis [28].

Metabolic inflammation and an excessive amount of adipose tissue lead to an increase in non-specific inflammatory biomarkers, such as C-reactive protein (CRP). It has been observed that the CRP concentration in patients with moderate and severe psoriasis is significantly higher than in healthy individuals [7]. Moreover, the long-term CRP concentration over $10 \mathrm{mg} / \mathrm{l}$ is associated with $4 \%$ risk of death due to cardiovascular diseases (CVD) in 10 years. For that reason, this simple marker of inflammation has currently been regarded as one of the most important prognostic factors for future cardiovascular events [49].

\section{Consequences of metabolic disturbances in psoriasis}

According to the theory of "psoriatic march", the above-described metabolic disorders lead to endothelial damage, facilitate the development of atherosclerotic 
plaques, which results in an increased risk of cardiovascular diseases in patients with psoriasis $[11,16]$.

In recent years a growing number of studies have revealed the association of psoriasis with other comorbidities, especially with CVD [50-55]. The risk of myocardial infarction and cerebrovascular disease is increased in psoriasis and correlates with disease severity. The patients with psoriasis have increased carotid-intimamedia thickness (cIMT), prevalence and severity of coronary artery calcification and atherosclerosis, and aortic vascular inflammation, all of which correlate positively with psoriasis severity [56-60]. Most of the cardiovascular risk factors including hypertension, dyslipidemia, obesity, T2DM and MS are more prevalent in psoriasis [60-63]. This association may be explained based on common pathogenic factors including inflammation and OS. The cytokine profile of psoriatic skin lesions and atherosclerotic vascular lesions show many similarities like an increased number of Th1 and Th17 lymphocytes and Th17-related cytokines (IL-6, IL-8, IL-17). Both diseases are also associated with similar ROS-signaling cascades including activation of the JAK-STAT, NF- $\mathrm{BB}$ and MAPK cascades [57, 64].

The combination of inflammation, OS and dyslipidemia leads to endothelial dysfunction. Patients with psoriasis present increased cIMT and stiffness of arteries combined with deteriorated vasodilation and decreased elasticity of vessels [65-69]. In some studies, flow medi- ated dilation (FMD) of the brachial artery was measured with ultrasound. FMD was significantly decreased comparing to the controls, which directly indicates dysfunction of endothelium $[69,70]$.

These findings are in agreement with studies revealing an increased number of circulating endothelial cells (CEC) and a decreased number of circulating endothelial progenitor cells (CEPCs) in psoriatic patients [71, 72]. The elevated number of CEC in psoriasis may be a result of both endothelium impairment and increased angiogenesis. CEPCs play a crucial role in maintenance of vascular homeostasis and regeneration of endothelium. As mentioned above, the impaired number and function of CEPCs have been found in patients with psoriasis. Both the increased number of CEC and the decreased number of CEPCS are considered as a marker of CVD risk.

The indisputable relationship between psoriasis and cardiovascular diseases resonated in the study of the European Society of Cardiology consensus regarding the prevention of CVD in 2012. Psoriasis was included as one of the diseases which carry an increased risk of the development of CVD [73].

\section{Metabolomic and proteomic changes in psoriasis}

Metabolomics provide a molecular fingerprint of metabolites involved in cellular activity and play a crucial role in understanding the functional changes in dis-

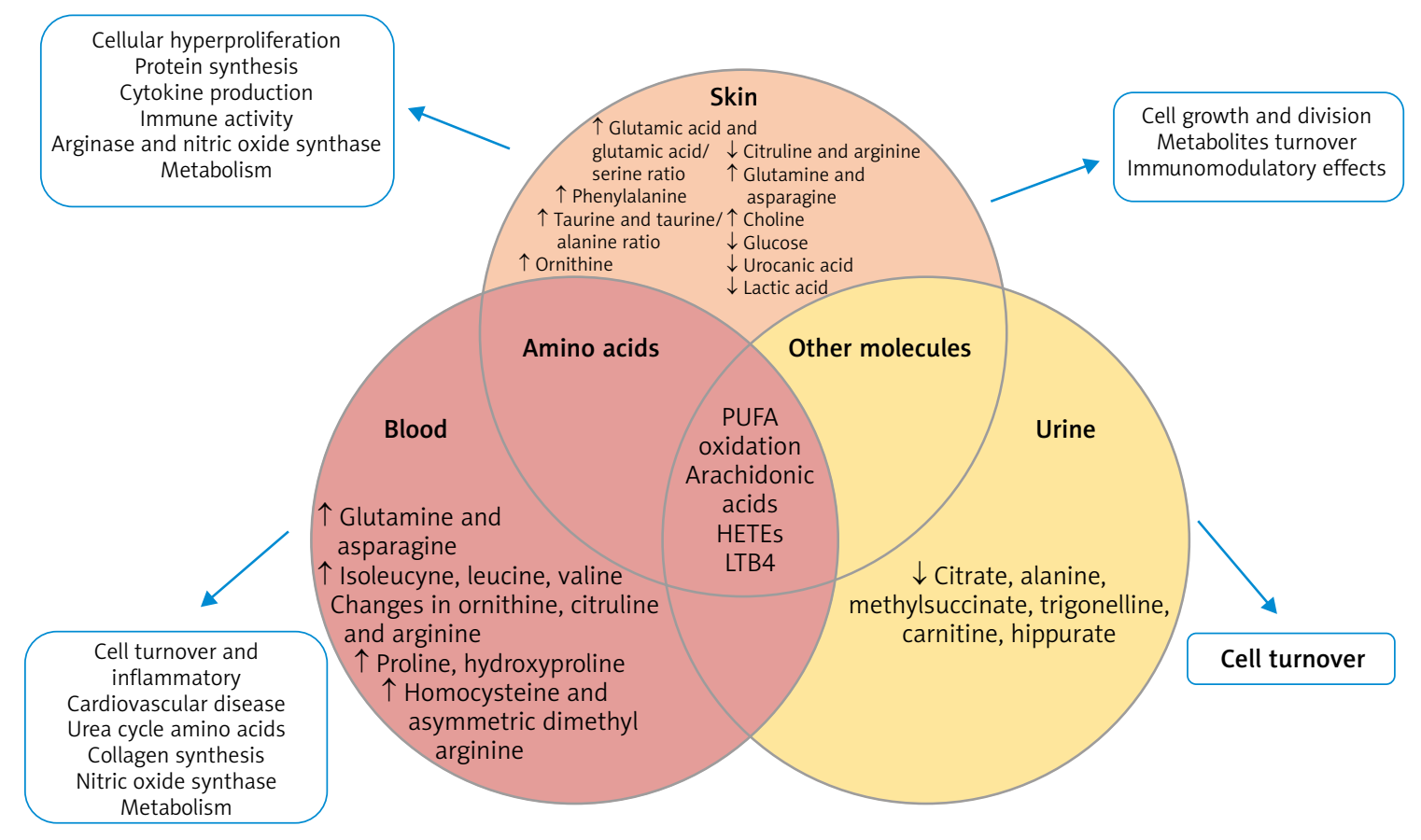

PUFA - polyunsaturated omega-6 fatty acids, HETES - hydroxyeicosatetraenoic acids, LTB4 - leukotriene B4.

Figure 4. Metabolomic changes in psoriasis [74-76] 
ease development. Figure 4 and Table 1 represents the main metabolomic changes across different body fluids (blood and urine) as systemic perturbation of metabolic processes and skin as local changes caused by psoriasis $[74,75]$. Biological material used for analysis changes in polyunsaturated $\omega-6$ fatty acids oxidation process. The main difference in psoriasis patients were observed in the amino acid level in skin and blood samples which were involved in several metabolic pathways (urea cycle, cell turnover, cardiovascular disease, nitric oxide synthase, collagen synthesis, protein synthesis or immune activity) [74-76]. Other molecules identified in psoriatic skin and urine provide information about cell growth and division, metabolite turnover and immunomodulatory effects, they were used to track response to treatment and determine disease severity. The investigation of the metabolome in skin, blood and urine provide a wide range of information about local and systemic increases in inflammation, cell turnover and proliferation, highlighting novel ideas for disease differentiation (psoriasis vs. PsA) [74].
Several metabolomics studies had confirmed that psoriasis is a chronic, immune-mediated, inflammatory skin disease. The field of proteomics has introduced some novel mechanisms and hypotheses that can be involved in disease progression. Proteomics provide the information about protein identification and differentiation in disease progression using different separation techniques coupled with mass spectrometry. The main purpose of proteomic studies is to define novel biomarkers for diagnostics, monitoring and prognostics of psoriasis [75-78]. Figure 4 represents some of the observed changes in protein distribution in psoriasis disease in skin, plasma and urine samples. They can be divided into three groups based on their functionality: discovery of the novel mechanism and hypothesis, biomarkers for prognostics and diagnostics of psoriasis and for monitoring treatment efficacy and toxicities [77]. Proteomic studies confirm an immune response as a basis of psoriasis progression. Participation in psoriasis, mechanisms that are involved in lipid metabolism and vitamin D regulation or cell leakage and altered protease

Table 1. Metabolomic changes in psoriasis [74]

\begin{tabular}{|c|c|c|c|}
\hline \multicolumn{2}{|c|}{ Metabolite } & Metabolic processes & Implications \\
\hline \multirow[t]{10}{*}{ Skin } & $\begin{array}{c}\uparrow \text { Glutamic acid, } \uparrow \text { glutamic acid/serine } \\
\text { ratio }\end{array}$ & $\begin{array}{l}\text { Cellular hyperproliferation, protein synthesis } \\
\text { and cytokine production }\end{array}$ & \multirow[t]{3}{*}{$\begin{array}{l}\text { Hyperproliferative or } \\
\text { hypermetabolic states }\end{array}$} \\
\hline & $\uparrow$ Choline & Cells growth and division & \\
\hline & $\begin{array}{l}\downarrow \text { Glucose, myo-inositol and valine-leucine/ } \\
\text { isoleucine ratio }\end{array}$ & Metabolite turnover in cells proliferation & \\
\hline & $\uparrow$ Phenylalanine & Immune activity $\rightarrow$ metabolite accumulation & \multirow{3}{*}{$\begin{array}{l}\text { Metabolic pathway } \\
\text { secondary to inflammation }\end{array}$} \\
\hline & $\uparrow$ Taurine and taurine/alanine ratio & $\begin{array}{c}\text { Inflammatory lesions and tissue exposed } \\
\text { to OS }\end{array}$ & \\
\hline & $\downarrow$ Urocanic acid & Immunomodulatory effects & \\
\hline & $\downarrow$ Lactic acid & Metabolism in sweat glands and keratinocytes & \multirow{2}{*}{$\begin{array}{l}\text { Disruption of normal } \\
\text { epidermal structures and } \\
\text { function }\end{array}$} \\
\hline & $\downarrow$ Citrulline & Hyperproliferative epidermis & \\
\hline & $\uparrow$ Ornithine and $\downarrow$ arginine & $\begin{array}{c}\text { Arginase } 1 \text { and inducible nitric oxide synthase } \\
\text { metabolism }\end{array}$ & \multirow[t]{2}{*}{$\begin{array}{l}\text { Keratinocyte } \\
\text { hyperproliferation }\end{array}$} \\
\hline & $\begin{array}{l}\text { 个 Arachidonic acid, hydroxyeicosatetraenoic } \\
\text { acid, leukotriene B4 }\end{array}$ & PUFA- 6 oxidation & \\
\hline \multirow[t]{4}{*}{ Blood } & $\begin{array}{l}\uparrow \text { Glutamine and asparagine, } \\
\uparrow \alpha \text {-Ketoglutaric acid }\end{array}$ & Cell turnover and inflammation & Hyperproliferation and OS \\
\hline & $\begin{array}{c}\uparrow \text { Isoleucine, leucine, valine } \\
\text { Changes in ornithine, arginine, citrulline } \\
\uparrow \text { Proline, hydroxyproline }\end{array}$ & $\begin{array}{c}\text { Cardiovascular disease: } \\
\text { urea cycle, amino acids } \\
\text { Collagen synthesis (psoriatic arthritis) }\end{array}$ & \multirow{2}{*}{$\begin{array}{l}\text { Assessment of psoriasis } \\
\text { and track response to } \\
\text { treatment, classifying } \\
\text { disease }\end{array}$} \\
\hline & $\begin{array}{l}\uparrow \text { Homocysteine and asymmetric dimethyl } \\
\text { arginine }\end{array}$ & $\begin{array}{c}\text { CVD } \\
\text { nitric oxide synthase metabolism }\end{array}$ & \\
\hline & $\begin{array}{c}\downarrow \text { Arachidonic acid, } \uparrow \text { leukotriene B4, } \\
\text { platelet activating factor }\end{array}$ & $\begin{array}{c}\text { Arachidonic acid pathway, Inflammatory } \\
\text { response }\end{array}$ & $\begin{array}{c}\text { Keratinocyte } \\
\text { hyperproliferation }\end{array}$ \\
\hline \multirow[t]{2}{*}{ Urine } & $\begin{array}{c}\downarrow \text { Hydroxyeicosatetraenoic acid } \\
\uparrow \text { Tetranor hydroxyeicosatetraenoic acid }\end{array}$ & PUFA- 6 oxidation & Microsomal $\beta$-oxidation \\
\hline & $\begin{array}{l}\downarrow \text { Citrate, alanine, methylsuccinate, } \\
\text { trigonelline, carnitine, hippurate }\end{array}$ & Cell turnover & $\begin{array}{l}\text { Track response to } \\
\text { treatment, disease severity }\end{array}$ \\
\hline
\end{tabular}


A. Owczarczyk-Saczonek, D. Purzycka-Bohdan, B. Nedoszytko, A. Reich, A. Szczerkowska-Dobosz, J. Bartosińska, A. Batycka-Baran, R. Czajkowski, I.T. Dobrucki, L.W. Dobrucki, M. Górecka-Sokołowska, A. Janaszak-Jasiecka, L. Kalinowski, et al.

activity are not clearly understood and need to be confirmed [3]. Skin proteomic analysis proposed some molecules (neural cell adhesion molecule L1 (L1CAM/CD171) and dipeptidyl peptidase 4 (DDP4/CD26)) as novel biomarkers for human cutaneous mast cells in normal skin, psoriasis, and mastocytosis. They are important for skin homeostasis and their presence in mast cells could help to understand the roles of mast cells in skin under normal and pathological states. Desmoplakin, complement C3, polymeric immunoglobulin receptor and cytokeratin 17 in plasma of psoriasis patients were found to correlate with the PASI score and has the potency to predict disease severity [77]. Drugs used in conventional psoriasis treatment (methotrexate and cyclosporine) are associated with renal and liver toxicities. Proteomics studies have shown several proteins which could serve as potential biomarkers of cyclosporine-induced nephrotoxicity and methotrexate-induced hepatic fibrosis $[79,80]$. Metabolomics and proteomics studies can be performed in two pathways: untargeted and targeted approaches. Untargeted analysis provides a global picture of metabolic or proteomic activity and was used to differentiate between the healthy people

Table 2. Novel mechanisms and hypotheses of the disease

\begin{tabular}{|c|c|c|}
\hline Protein & Patients & Results/implications \\
\hline Proteome profile (skin) & $\begin{array}{l}\text { Acute psoriasis/chronic plaque } \\
\text { psoriasis/nickel-induced contact } \\
\text { eczema }\end{array}$ & $\begin{array}{l}\text { The proteome profiles of acute psoriasis and contact } \\
\text { eczema are similar but different from chronic plaque } \\
\text { psoriasis, duration of the disease process may affect the } \\
\text { skin proteome pattern }\end{array}$ \\
\hline $\begin{array}{l}\text { Thymosin } 4 \text {, talin } 1 \text {, actin, filamin, } \\
\text { profilin, and calgranulins } \\
\text { a and } b \text { (plasma) }\end{array}$ & Psoriasis/healthy & $\begin{array}{l}\text { Cytoskeletal and actin-binding } \\
\text { Proteins/peptides as well as } \mathrm{Ca}^{2+} \text {-binding components } \\
\text { suggested disease-related cell leakage and altered } \\
\text { protease activity }\end{array}$ \\
\hline $\begin{array}{l}\text { Glutathione S transferase } 1 \text {, } \\
\text { peroxiredoxin } 2 \text {, and SFN protein } \\
\text { (skin) }\end{array}$ & Psoriasis/healthy & $\begin{array}{l}\text { Abnormalities in cell proliferation, the regulatory/ } \\
\text { balancing system, and the inflammatory response }\end{array}$ \\
\hline Saliva proteome & Plaque psoriasis/diabetic/healthy & $\begin{array}{l}\text { Levels in plaque psoriasis and diabetic patients were } \\
\text { similar, both differed from normal saliva }\end{array}$ \\
\hline $\begin{array}{l}\text { Proteins involved in lipid metabolism } \\
\text { and vitamin D regulation, proteins } \\
\text { involved in the immune response and } \\
\text { signal transduction (plasma) }\end{array}$ & Psoriatic patients & $\begin{array}{l}\text { Decreased levels of proteins involved in lipid metabolism } \\
\text { and vitamin D regulation } \\
\text { Increased level of proteins in the immune response and } \\
\text { signal transduction }\end{array}$ \\
\hline \multicolumn{3}{|c|}{ Biomarker discovery for diagnostics and prognostics } \\
\hline $\begin{array}{l}\text { Profilin } 1 \text {, lysozyme } C \text {, and neutrophil } \\
\text { gelatinase-associated lipocalin (NGAL) } \\
\text { (plasma) }\end{array}$ & $\begin{array}{l}\text { Psoriatic lesional skin/ } \\
\text { non-lesional area }\end{array}$ & $\begin{array}{l}\text { Only profilin } 1 \text { had a tendency to increase in the psoriatic } \\
\text { plasma }\end{array}$ \\
\hline $\begin{array}{l}\text { Neural cell adhesion molecule } \\
\text { L1 (L1CAM/CD171) and dipeptidyl } \\
\text { peptidase } 4 \text { (DDP4/CD26) (skin cells) }\end{array}$ & $\begin{array}{l}\text { Mast cell proteome/other } \\
\text { skin cells (i.e., fibroblasts, } \\
\text { keratinocytes, melanocytes) }\end{array}$ & Skin homeostasis \\
\hline $\begin{array}{l}\text { Desmoplakin, complement } \mathrm{C} 3 \text {, } \\
\text { polymeric immunoglobulin receptor, } \\
\text { and cytokeratin } 17 \text { (plasma) }\end{array}$ & Psoriasis/healthy & Correlated with the PASI score \\
\hline \multicolumn{3}{|c|}{ Monitoring treatment efficacy and toxicities } \\
\hline CD11a & $\begin{array}{l}\text { Psoriatic skin after efalizumab } \\
\text { treatment }\end{array}$ & Vast diversity of inflammatory epitope co-localization \\
\hline IL-17A, $\beta$-defensin 2 (skin and serum) & $\begin{array}{l}\text { Psoriasis/healthy before } \\
\text { and after treatment with } \\
\text { secukinumab }\end{array}$ & $\begin{array}{l}\text { Level of } \beta \text {-defensin } 2 \text { was correlated with the IL-17A } \\
\text { level and PASI score in psoriatic patients after treatment } \\
\text { a significant reduction of } \beta \text {-defensin } 2 \text { was observed }\end{array}$ \\
\hline $\begin{array}{l}\mathrm{N} \text {-cadherin, inter-trypsin inhibitor } \\
\text { heavy chain } \mathrm{H} 4 \text {, haptoglobin, and } \\
\text { serotransferrin (urine) }\end{array}$ & $\begin{array}{l}\text { Psoriatic patients treated with } \\
\text { low-cumulative dose }(<1500 \mathrm{mg}) \\
\text { or high-cumulative dose } \\
\text { (>1500 mg) of methotrexate }\end{array}$ & $\begin{array}{l}\text { Potential biomarkers for methotrexate-induced hepatic } \\
\text { fibrosis }\end{array}$ \\
\hline $\begin{array}{l}\text { Proteins involved in the endoplasmic } \\
\text { reticulum stress response, protein } \\
\text { folding, apoptosis, metabolism, } \\
\text { transport, cytoskeletal assembly, and } \\
\text { nuclear/RNA regulation }\end{array}$ & $\begin{array}{l}\text { Not specific to psoriatic } \\
\text { cyclosporine treatment }\end{array}$ & $\begin{array}{l}\text { Potential biomarkers of cyclosporine-induced } \\
\text { nephrotoxicity }\end{array}$ \\
\hline
\end{tabular}


and psoriasis patients, proposing new targets for diagnosis or metabolism understanding. Targeted analysis concentrates on metabolite or protein of interest for precise measurement for diagnostic, prognostic or drug treatment monitoring [78] (Figure 5 and Table 2).

\section{Nutrigenomics: dietary ingredients affect the regulation of the inflammatory process in psoriasis}

Chronic inflammatory skin disease - psoriasis presents complex genetic, epigenetic and environmental etiology, including dietary background. It is believed that in the presence of specific genetic variants, complex disease phenotype requires nutritional and lifestyle-associated triggering factors. Interestingly, the putative interplay between the skin, the immune system and the nutrients has been revealed. Thus, the nutrigenomic approach has been applied in human studies of psoriasis etiology and also treatment. Nutrigenomics involves the effects of dietary nutrients on cellular gene expression and gene methylation, and ultimately, phenotypic changes. To understand the complex relationships between nutrition and psoriasis, only few studies have investigated the effect of diet and lifestyle on the psoriasis disease risk [74].

Psoriasis is treated with compounds targeting the pro-inflammatory molecules i.e. TNF inhibitors. Approximately one-third of the patients do not respond to the treatment. Perhaps one of the factors responsible for the lack of efficacy is nutritional triggers. Unfortunately, stud- ies regarding nutrigenomics in psoriasis, explaining the putative mechanisms linking nutrients and inflammation resulting in psoriasis development, are rare. The identification of new biomarkers or patterns of biomarkers that link nutrition with disease and its treatment represents one of the major challenges of omics sciences in the psoriasis.

\section{The effect of diet on mi-RNA expression}

Although in the past two decades there has been increasing evidence to support a modulating role of nutrients in several physiological and pathological aspects, the exact mechanisms remain elusive. Among the proposed hypotheses, epigenetic DNA reprogramming has been assessed through the evaluation of stimulated gene expression and mRNA transcription, DNA silencing through CpG DNA modification (methylation); histone modification (acetylation, methylation); and expression of small noncoding RNAs, known as microRNAs (miRNAs) [81].

As elsewhere, miRNAs were powerful regulators of gene expression and transcription, participating in a number of metabolic functions of cells and different disease development and progression.

It has been documented that natural agents, presumably exerting antioxidative and anti-inflammatory properties, such as polyphenolic derivatives present in fruits and wine, as well as Coenzyme Q10, vitamin $\mathrm{D}$, and microelement selenium were able to modulate miRNA expression in different chronic diseases [82, 83] - Table 3.

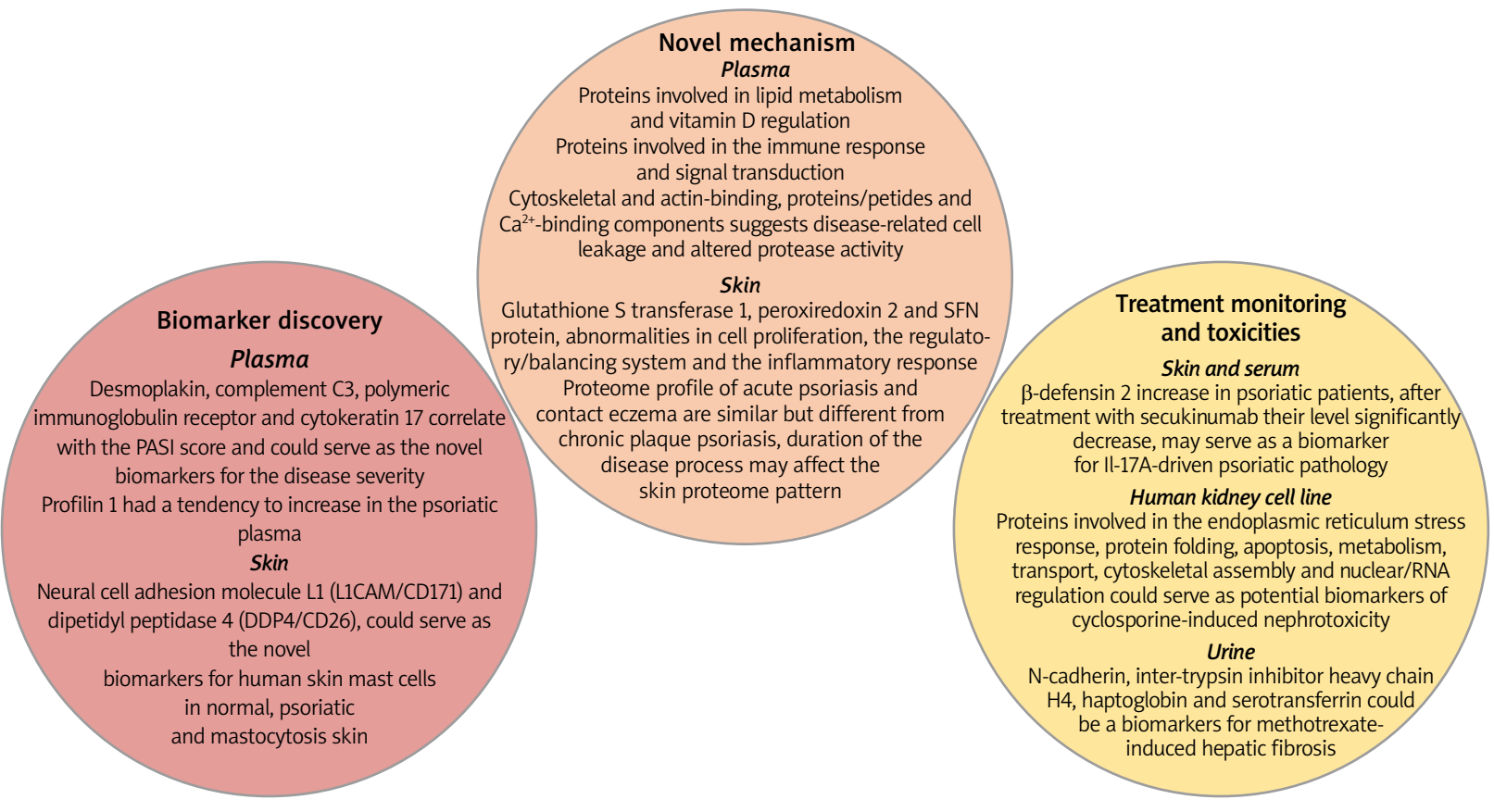

Figure 5. Proteomic changes in psoriasis [75-80] 
A. Owczarczyk-Saczonek, D. Purzycka-Bohdan, B. Nedoszytko, A. Reich, A. Szczerkowska-Dobosz, J. Bartosińska, A. Batycka-Baran, R. Czajkowski, I.T. Dobrucki, L.W. Dobrucki, M. Górecka-Sokołowska, A. Janaszak-Jasiecka, L. Kalinowski, et al.

Table 3. Dietary compounds and their effects on micro-RNA expression and psoriasis (adapted from Kocic et al. [85])

\begin{tabular}{|c|c|c|}
\hline $\begin{array}{l}\text { Dietary } \\
\text { compound }\end{array}$ & $\begin{array}{l}\text { Effect on mi-RNA } \\
\text { expression }\end{array}$ & Local and systemic effects \\
\hline Resvestratol & $\downarrow$ miR-21 & $\begin{array}{l}\text { Reduction of expression of transcription factor NF- } \kappa B \\
\text { Reduction of synthesis of proinflammatory cytokines: TNF- } \alpha \text {, IL-1 } \beta, \text { IL- } 6, \text { IL- } 8 \\
\text { Downregulation of MAPK, JANUS kinases and AP-1 transcription factor }\end{array}$ \\
\hline Curcumin & $\begin{array}{l}\downarrow \text { miR-155 } \\
\downarrow \text { miR-21 }\end{array}$ & $\begin{array}{c}\text { Downregulation of expression of AKT, and JANUS, AP-1 transcription factor, and mTOR pathway } \\
\text { Reduction of expression of transcription factor NF- } \kappa B \\
\text { Decrease of TNF- } \alpha \text { and IL- } 6 \text { synthesis }\end{array}$ \\
\hline Quercetin & $\uparrow \mathrm{miR}-146$ & $\begin{array}{l}\text { Decreaseof expression of TNF- } \alpha, \text { IL- } 6 \text { and IL-17 } \\
\text { Reduction of expression of transcription factor NF- } \mathrm{KB}\end{array}$ \\
\hline Vitamin D & $\begin{array}{l}\uparrow \operatorname{miR}-125 b \\
\downarrow \text { miR-155 }\end{array}$ & $\begin{array}{l}\text { Reduction of expression of transcription factor NF- } \kappa \text { B } \\
\text { Decreaseof TNF- } \alpha \text { and IL- } 6 \text { synthesis } \\
\text { Decrease of keratinocytes proliferation }\end{array}$ \\
\hline
\end{tabular}

\section{miRNA-21 expression and diet}

One of the most prominent miRNAs related to psoriasis is miR-21, present in different isomiR forms, which differ at the $3^{\prime}$ end. The main target of miRNA-21 contributing to chronic inflammation seems to be the derepression of TNF- $\alpha$ synthesis. miR-21 is also a promoter of the inflammatory cascade and an apoptotic suppressor [84-87].

Dietary modulations of miRNA-21 expression were examined in various in vivo and in vitro studies. Resveratrol, normally present in red wine, red grape juice, mulberries and peanuts is a powerful epigenetic modulator of miRNA-21 capable of downregulating miRNA-21 in different cell culture models [88, 89].

Curcumin, is a yellow polyphenol diferuloylmethane, obtained from curcuma (Curcuma longa) that has been documented to possess antioxidant and anti-inflammatory properties. Clinical studies have documented that miR-21 and miR-155 expression decreased after daily intake of curcumin. This decrease was followed by a subsequent suppression of key proliferation kinases, such as AKT kinase and TOR pathway, JNK kinase and transcription factor AP-1. The inflammation was attenuated by decreased NF- $\kappa$ B activation, TNF- $\alpha$ and IL- 6 synthesis [90].

\section{Micro-RNA- 155 is highly overexpressed in psoriatic skin}

In vitro and in vivo experiments indicated that resveratrol and quercetin have a potential benefit on miR155 expression [88, 90,91]. The downregulation of the expression of miR-155 was followed in mice by the inhibition of NF- $\kappa$ B activation and the consequent anti-inflammatory effect. miR-155 was also downregulated after vitamin D treatment in both in vitro and in vivo experiments. The anti-inflammatory effect proceeds through decreased NF- $\mathrm{KB}$ signaling and p65 subunit reduction $[92,93]$

\section{miR-125b is downregulated in both keratinocytes and peripheral blood in psoriasis}

This consequently leads to an increased keratinocyte proliferation rate, together with altered differentiation and an upregulated inflammatory cascade by de-repressed mRNA for TNF- $\alpha$. It targets FGFR-2, TNF $\alpha$, P63 and NOTCH1 genes and increases keratinocyte differentiation and decreases their proliferation. Some data indicate the role of diet on miR-125b expression. In vitro studies indicated that vitamin D treatment was able to increase the miR-125b level in cultures of prostatic epithelial cells [94]. Among the flavonoids documented to have a potential benefit on miR-125b expression is quercetin that has beneficial effects on miR-155 expression [91, 95] (Figure 6).

\section{The role of diet in the regulation of the inflammatory process in psoriasis}

The occurrence of psoriatic plaques is determined by both genetic and environmental factors. Diet, similarly to infections and stress, is one of the latter, but still underestimated [94]. Recent studies have revealed that decrease of the inflammatory potential of the diet can be used as a preventive measure in patients at risk of psoriasis and PsA [96, 97].

Some psoriatic patients introduce various, sometimes controversial diets that are offered by alternative medicine because of lack of efficacy with conventional treatment [98]. However, psoriasis is frequently associated with impaired quality of life and depression which may independently lead to changes in dietary habits.

Psoriatic patients are linked with poor nutrition. According to the National Health and Nutrition Examination Survey (NHANES) study, the nutritional status concerning proteins, saturated and polyunsaturated fatty acids, vitamins, antioxidants and total calorie intake have been analyzed. Interestingly, a positive correlation between BMI, increased level of vitamin A and $\alpha$-carotene and nega- 


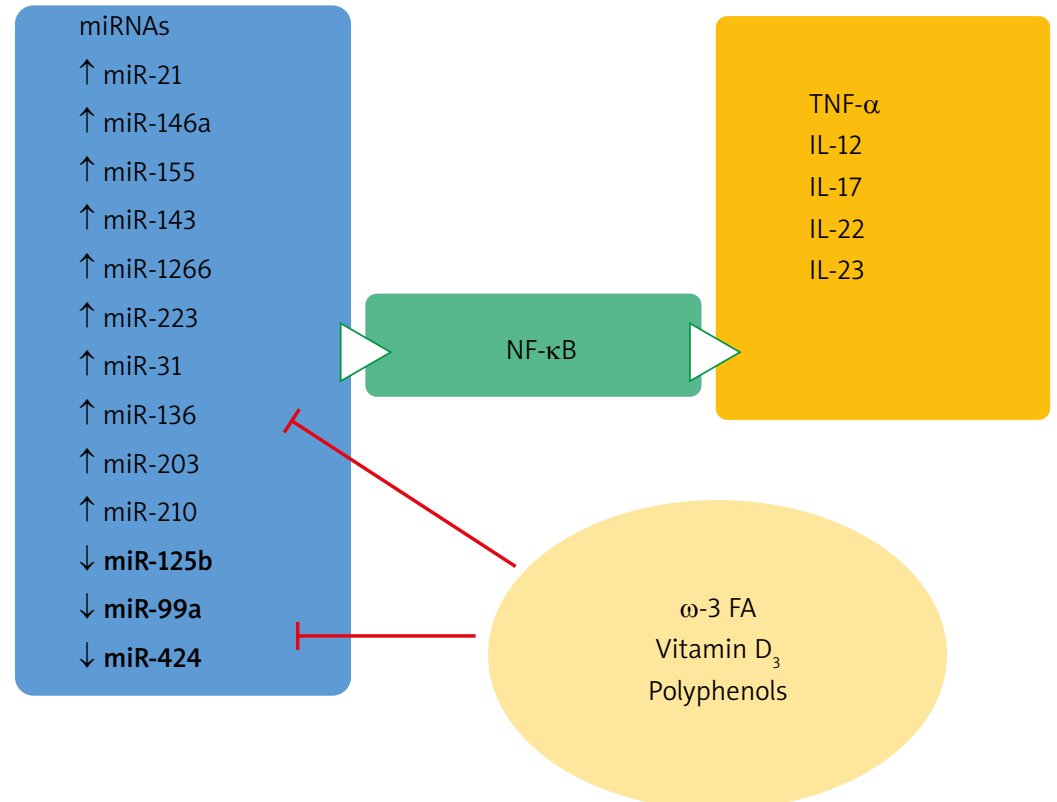

Figure 6. The role of micro-RNA in psoriatic skin (adapted from Kocic et al. [85])

tive correlation between simple carbohydrates intake and psoriasis prevalence [99] were noted. Recent studies have evaluated the empirical dietary inflammatory pattern (EDIP) in order to identify dietary nutrients stimulating the production of inflammatory state biomarkers (IL-6, CRP, and TNF- $\alpha$ receptor 2) [100]. However, the Nurses' Health Study II which evaluated EDIP every 4 years has not found any correlation between pro-inflammatory diet and increased prevalence of psoriasis. In addition, a non-significant correlation between psoriatic arthritis and pro-inflammatory diet was observed [99].

High energy diet leads to increased weight and accumulation of visceral fatty tissue, promoting meta-inflammation. Western diet is rich in saturated fatty acids which are increasing the serum level of FFA. The studies have confirmed that this may directly initiate the exacerbation of psoriatic inflammation. Saturated fatty acids induce pro-inflammatory response in myeloid cells which consequently leads to activation of keratinocytes [101].

The positive effect of low-calorie diet is not only weight reduction, but also is driven by low arachidonic acid intake. This leads to a decrease in the pro-inflammatory metabolite level - leukotriene B4, less activity of lymphocytes CD4+ and increase of the anti-inflammatory IL-4 level. Vegetarian diet is also associated with low intake of arachidonic acid and a reduced level of lactoferrin, the marker of neutrophil activation [102, 103].

The positive effect of low-calorie diet results in decreased levels of ROS. The neutrophils are the source of ROS in psoriatic plaques (Munro's micro-abscesses) and release myeloperoxidase [104]. ROS damage endothelium and increase microvascular permeability. This leads to pro-inflammatory cells migration and promotes inflammatory state [102].

Oxidative stress may also stimulate dendritic cells (DC) to activate effector T-cells, promote pro-inflammatory cytokines production and angiogenesis and activate transcription factors in keratinocytes leading to their hyperproliferation. In addition, ROS may increase the activity of transcription factors: MAPK, NF- $\mathrm{B}$ and JAK-STAT $[104,105]$.

Therapeutic fasting remains controversial in patients with psoriasis. It can promote autophagy, which is a selected degradation of damaged organelles and proteins in order to maintain cellular homeostasis. The impairment of this process can cause malignancies, neurodegenerative and autoimmune disorders. It has been reported that cultural or religious fasting (such as Ramadan - fasting $17 \mathrm{~h}$ daily for 1 month) was associated with a statistically significant decrease in the CRP level, reduction in PASI, and indicators of PsA activity [106].

Many studies have confirmed the increased level of OS markers in psoriatic patients. It has been observed that the levels of malondialdehyde in plasma or serum, lipid peroxides or nitric oxide were increased while antioxidant levels (thiol linked with albumin), vitamin $\mathrm{E}$ in serum and activity of major antioxidants (erythrocyte superoxide dismutase, catalase and peroxidase) were decreased, which correlated with PASI [104, 105]. The consequence of OS is lipid peroxidation and oxidization of LDL (ox-LDL - the main factor of atherosclerosis). In addition, OS leads to an increase in eicosanoids and pro-inflammatory thrombox- 
ane production [96]. Delphinidin, an antioxidant (a plant pigment that can be found in fruits: grapes, blueberries, elderberries, cranberries) inhibits keratinocytes proliferation and inflammation in psoriasis [107].

Omega-3 and 6-PUFA are not synthesized by humans and according to the National Institutes of Health Panel should be administered in a ratio of $1: 1.8$. Unfortunately, this recommended balance in the Western diet is severely impaired and reduced to a ratio of $1: 20$. This imbalance is associated with the significant increase in overweight and obesity. Moreover, the PUFA exerts a different effect on adipose tissue in terms of adipogenesis, lipid homeostasis, the gut-brain axis and systemic inflammation which may lead to promotion of metabolic disorders and atherosclerosis $[108,109]$. Omega- 6 acid is linoleic acid which is a precursor of arachidonic acid (AA). Arachidonic acid metabolites (PGE2 and LTB4) have pro-inflammatory effects and may promote neutrophil chemotaxis and enhance epidermal cells proliferation.

Omega- 3 fatty acids ( $\alpha$-linoleic acid and its derivatives) inhibit the release of AA from cell membrane phospholipids and compete with AA for the same enzymes, which results in production of anti-inflammatory molecules, such as LTB5. It has been observed that LTB5 is a 10-times less potent chemotactic agent in comparison to LTB4 and is a weaker keratinocyte proliferation stimulator [102, 110, 111]. It has been also found that $\omega-6$ fatty acids may stimulate the production of pro-inflammatory cytokines such as IL-1, IL- 8 and TNF- $\alpha$, whereas $\omega$ - 3 fatty acids have the opposite effect by reducing the activation of signaling paths of NF- $\kappa$ B, PPAR-g [102, 110, 111].

The popularity of vitamin $D_{3}$ supplementation has raised hope in its potentially beneficial effect in psoriasis treatment. The skin represents a key organ in the vitamin D endocrine system, acting as a site of vitamin D synthesis as well as a target tissue for biologically active vitamin D metabolites. Moreover, autoimmunity has been associated with vitamin D deficiency and resistance, with gene polymorphism related to vitamin D metabolism [112]. Keratinocytes are involved in the autonomic pathway of vitamin D synthesis using CYP27B1 for the most active vitamin D metabolite, 1,25-dihydroxyvitamin $\mathrm{D}_{3}\left(1,25(\mathrm{OH}) \mathrm{D}_{3}\right.$ or calcitriol). Several studies have indicated that vitamin $25(\mathrm{OH}) \mathrm{D}$ is deficient in patients with psoriasis compared to healthy people $[113,114]$. Moreover, this decrease was irrespective of age, gender, BMI and PASI score and tends to worsen in winter [115-117].

The role of vitamin D as a main regulator of skin physiology is very complex. It was observed that topical application of vitamin $D_{3}$ leads to down-regulation of antiapoptotic protein $\mathrm{Bcl}-\mathrm{xl}$ [118]. That involves regulation of keratinocyte proliferation, differentiation and apoptosis, regulation of the cutaneous immune system (inhibition of T cell proliferation, Tregs induction), down-regulation of pro-inflammatory cytokines, stimulation of antimicro- bial peptides expression, regulation of barrier integrity and permeability [113]. This concept was also supported by the observation that its derivatives have been used in topical treatment. However, further research is necessary to establish the beneficial effect of vitamin $D_{3}$ in psoriasis and its routes of delivery [114]. This could include testing of novel non-calcemic hydroxyderivatives that are products of an alternative pathway of vitamin D activation [119]. The novel forms of vitamin $\mathrm{D}$ act also on alternative nuclear receptors including retinoic orphan receptor $(\mathrm{ROR}) \gamma$, a master regulator of IL-17 [120, 121]. They also inhibit NF$\kappa \mathrm{B}$ activity [122].

Cyclitols, natural sugar alcohols, are compounds with protective properties which have been found to be effective in IR, lipid disorders and polycystic ovary syndrome. Their immunomodulating effect may suggest that some of them such as D-pinitol, D-chiro-inositol and myo-inositol may be used in psoriasis treatment [102]. It has been observed that these compounds normalize the balance between Th1, Th17 and Th2 lymphocytes, inhibit pro-inflammatory cytokine production (TNF- $\alpha$ ), stimulate the keratinocyte apoptosis, inhibit oxidative stress and angiogenesis [98]. Moreover, vegetable food containing cyclitols may play an additional role in psoriasis prevention [102].

The Mediterranean diet is highly recommended for patients with psoriasis. This diet reduces systemic inflammation and thus the risk of metabolic syndrome, CVD and other chronic inflammatory diseases [114, 123]. This diet is characterized by high intake of fruits and vegetables, legumes, cereals, fish, nuts and extra virgin olive oil which is an important source of monounsaturated fat (MUFA). This type of fat improves the lipid profile by reducing LDL levels and increasing HDL levels, thus leading to CRP and $\mathrm{IL}-6$ reduction. The meat, milk products, eggs and alcohol intake in this diet is low to intermediate. This diet provides dietary fiber, antioxidants and polyphenols [114, 123, 124]. Recent meta-analyses have confirmed the anti-inflammatory beneficial effects of the Mediterranean diet [102].

The Italian scientists have analyzed randomized controlled trials concerning the nutritional strategies such as hypocaloric diet, vitamin D, oil fish, selenium and zinc supplementation in patients with psoriasis. It has been shown that weight reduction in addition to healthy lifestyle have exerted beneficial effects in terms of psoriatic plaques reduction (PASI) in patients with moderate to severe disease. Supplementation of zinc, selenium and $\omega$-3 fatty acids have proved beneficial in patients with psoriasis [125].

\section{Dietary recommendations in patients with psoriasis}

There are not enough data, especially from randomized controlled trials, to recommend specific dietary interventions in psoriatic patients. In a recent trial, $86 \%$ of patients adopted dietary modifications in order to mitigate the disease severity [126]. The survey study in coop- 
Table 4. Diet recommendations for patients with psoriasis

\begin{tabular}{|c|c|}
\hline Recommended & Not recommended \\
\hline $\begin{array}{l}\text { - } 1 \text {-2 g of } \omega \text {-3 PUFAs per day (oily fish: sardines, salmon, } \\
\text { mackerel, herring, tuna and vegetable oils: linseed, rapeseed, } \\
\text { soybean, corn oil) - wild fish (not farmed), } \\
\text { - Consumption of antioxidants such as } 400 \text { mg of selenium per } \\
\text { day (oat, brown rice, pumpkin seeds, poultry, fish), 100-200 mg } \\
\text { of coenzyme Q per day, } 50 \text { mg of vitamin E per day and } \\
\text { polyphenols (grapes, apples, cocoa, cranberries, black currants) } \\
\text { - Supplementation of vitamin } D_{3} \text { (oily fish, fish oil) } \\
\text { - Only in case of gluten intolerance, glute-free diet is } \\
\text { recommended (elimination of wheat, rye, barley and oats) }\end{array}$ & $\begin{array}{l}\text { - Nightshade vegetables (tomatoes, paprika, chili-pepper, } \\
\text { eggplant, pepper) } \\
\text { - Red meat, animal fats and offal } \\
\text { - All types of alcohol should be avoided (except for a glass } \\
\text { of red wine containing resveratrol) } \\
\text { - Consumption of highly processed foods containing } \\
\text { preservatives and fried foods (damage of essential non- } \\
\text { saturated fatty acids in high temperature and formation } \\
\text { of harmful and carcinogenic compounds: acrolein and } \\
\text { acrylamide) } \\
\text { - Excessive consumption of products containing caffeine and } \\
\text { spicy food is not recommended }\end{array}$ \\
\hline
\end{tabular}

eration of the National Psoriasis Foundation has found that psoriatic patients in comparison to control subjects have eaten significantly less sugar, whole grain fiber, dairy and calcium. Moreover, psoriatic patients have consumed more fruits, vegetables and legumes in comparison to controls [126]. The largest percentage of patients reported improvements in the skin condition after reduction in alcohol (53.8\%), gluten (53.4\%), nightshade family intake (tomatoes, paprika, chili-pepper, eggplant and pepper) (52.1\%). This beneficial effect has also been associated with the increase in fish oil/omega-3 (44.6\%), vegetables (42.5\%) and oral vitamin D intake (41\%). In addition, Pagano alkaline, vegan and Paleolithic diets have been reported to exert a beneficial effect on skin lesions reduction $(72.2 \%, 70 \%$ and $68.9 \%$, respectively). Moreover, $41.8 \%$ of respondents have admitted that the main reason for adopting diet changes was an improvement in the health status [126].

The National Psoriasis Foundation review of dietary recommendations based on clinical evidence (Medline from 1 January 2014 to 31 August 2017) has confirmed the efficacy of weight-loss diet (strong recommendation). Gluten-free diet was recommended only in patients with serologically confirmed gluten intolerance. In patients with PsA there is a weak recommendation to administer vitamin $D$ and to reduce weight in hypocaloric diet in overweight and obese patients [127].

There is strong evidence that weight loss is beneficial in modifying the course of the disease as well as a gluten-free diet in patients with anti-gliadin antibodies [98, 126-129].

The increased intake of $\omega$-3 PUFA, folic acid, vitamins $A, D$ and $E$ may play a significant role due to their antiinflammatory properties [130-132]. Moreover, diet may modify gut microbiota by regulating the activity of Th17 and Treg. The importance of the gut-skin axis in pathogenesis of psoriasis has been recently documented [131].

It should also be noted that severe course of psoriasis may lead to deficiencies of nutrients (proteins, folic acid and antioxidants) due to excessive epidermal prolifera- tion and its rapid desquamation. Consequently, the decrease in total protein and serum albumin levels, increase in erythrocyte volume and reduction of hematocrit is observed. Finally, the patients with severe psoriasis require systemic treatment which also affects the nutritional status (Table 4) [98].

\section{Benefits of adopting optimal diet in psoriasis}

A low-calorie diet may be regarded as addition to standard therapy in psoriasis. Weight loss of $5-10 \%$ improves therapeutic response to cyclosporine-A treatment in obese patients with psoriasis and prolongs the remission period after successful treatment with methotrexate [123].

Moreover, microelements may improve the efficacy of methotrexate. The effects of treatment with addition of various antioxidants (vitamin C, zinc, selenium, bioflavonoids) and vitamin D in higher than recommended daily allowances were better than monotherapy (PASI reduction and a decreased level of pro-inflammatory cytokines: IL-1 $\beta$ and TNF- $\alpha$ ) [132].

Interestingly, diet may affect the pharmacokinetics of administered agents. The combined use of cyclosporine and grapefruit juice increase the bioavailability of the drug by $60 \%$ due to inhibition of cytochrome P450mediated metabolism. Therefore, the patients should be aware that it is necessary to avoid grapefruit juice during treatment [98].

The administration of vitamin A derivatives (acitretin, etretinate) however, can cause hypervitaminosis. The risk is increased when patients also use dietary supplements and food rich in vitamin A. The main signs and symptoms include headache, weakness, and anorexia. Moreover, retinoids may also affect the lipid profile: they increase triglycerides and cholesterol level. Therefore, during treatment, patients are advised to use $\omega$-3 PUFAs and reduce simple carbohydrates and alcohol intake [98, 133]. It has been shown that impairment of lipid and glucose metabolism was temporary and was not associated with 
changes in $\mathrm{BMI}$ and in the level of adipokines related to obesity (TNF- $\alpha$, resistin, adiponectin) $[98,133]$.

\section{Conclusions}

Psoriasis is a complex disease, associated with chronic comorbidities related to the systemic inflammation. Dermatologists should consider the patient holistically, and recommend the treatment based on a range of factors, including disease severity, quality of life impairment and comorbidities. Patients with psoriasis should be advised to adopt proper diet and dietician support.

\section{Acknowledgments}

This work is supported by grant of the Polish Ministry of Science and Higher Education no. 02-0066/07/253.

\section{Conflict of interest}

The authors declare no conflict of interest.

\section{References}

1. Deng Y, Chang C, Lu Q. The inflammatory response in psoriasis: a comprehensive review. Clin Rev Allergy Immunol 2016; 50: 377-89.

2. Owczarczyk-Saczonek A, Czerwińska J, Orylska M, et al. Evaluation of selected mechanisms of immune tolerance in psoriasis. Adv Dermatol Allergol 2019; 36: 315-24.

3. Chularojanamontri L, Charoenpipatsin N, Silpa-Archa N, et al. Proteomics in Psoriasis. Int J Mol Sci 2019; 20: 1141.

4. Owczarczyk-Saczonek A, Placek W. Interleukin-17 as a factor linking the pathogenesis of psoriasis with metabolic disorders. Int J Dermatol 2017; 56: 260-8.

5. Alberti KGMM, Zimmet P, Shaw J. The metabolic syndrome - a new worldwide definition. Lancet 2005; 366: 1059-62.

6. Longo M, Zatterale F, Naderi J, et al. Adipose tissue dysfunction as determinant of obesity-associated metabolic complications. Int J Mol Sci 2019; 20: 2358.

7. Owczarczyk-Saczonek A, Nowicki R. Pathophysiology of the relationship of psoriasis and metabolic disorders. Dermatol Rev 2013; 100: 125-31.

8. Horreau C, Pouplard C, Brenaut E, et al. Cardiovascular morbidity and mortality in psoriasis and psoriatic arthritis: a systematic literature review. J Eur Acad Dermatol Venereol 2013; 27: 12-9.

9. Toussirot E, Aubin F, Dumoulin G. Relationships between adipose tissue and psoriasis, with or without arthritis. Front Immunol 2014; 5: 368.

10. Rodríguez-Cerdeira C, Cordeiro-Rodríguez M, CarneroGregorio M, et al. Biomarkers of inflammation in obesitypsoriatic patients. Mediators Inflamm 2019; 2019: 7353420.

11. Owczarczyk-Saczonek A, Placek W. Związki łuszczycy z otyłością i nadwagą. Postępy Hig Med Dosw 2017; 71: 761-72.

12. Coimbra S, Catarino C, Santos-Silva A. The triad psoriasisobesity-adipokine profile. J Eur Acad Dermatol Venereol 2016; 30: 1876-85.

13. Naldi L, Addis A, Chimenti S, et al. Impact of body mass index and obesity on clinical response to systemic treatment for psoriasis. Dermatology 2008; 217: 365-73.
14. Han JH, Lee JH, Han KD, et al. Increased risk of psoriasis in subjects with abdominal obesity: a nationwide populationbased study. I Dermatol 2019; 46: 695-701.

15. Aune D, Snekvik I, Schlesinger S, et al. Body mass index, abdominal fatness, weight gain and the risk of psoriasis: a systematic review and dose-response meta-analysis of prospective studies. Eur J Epidemiol 2018; 33: 1163-78.

16. Boehncke WH, Boehncke S, Tobin AM, et al. The 'psoriatic march': a concept of how severe psoriasis may drive cardiovascular comorbidity. Exp Dermatol 2011; 20: 303-7.

17. Jin Y, Zhang F, Yang S, et al. Combined effects of HLA-Cw6, body mass index and waist-hip ratio on psoriasis vulgaris in Chinese Han population. J Dermatol Sci 2008; 52: 123-9.

18. Love TJ, Zhu Y, Zhang Y, et al. Obesity and the risk of psoriatic arthritis: a population-based study. Ann Rheum Dis 2012; 71: 1273-7.

19. Shipman AR, Millington GWM. Obesity and the skin. $\mathrm{Br}$ J Dermatol 2011; 165: 743-50.

20. Goldberg IJ, Eckel RH, Abumrad NA. Regulation of fatty acid uptake into tissues: lipoprotein lipase- and CD36-mediated pathways. J Lipid Res 2009; 50 Suppl: 86-90.

21. Szybiński Z. Otyłość a insulinemia. [In:] Insulinemia w zespole metabolicznym. Szybiński Z (ed.). Wyd Med Kraków 2003; 63-76.

22. Vega-Robledo GB, Oliva-Rico D, Rico-Rosillo G. Adipose tissue: function, adipokines, and alterations related with psoriasis. Sci J Clin Res Dermatol 2017; 2: 036-42.

23. Koleva DI, Orbetzova MM, Atanassova PK. Adipose tissue hormones and appetite and body weight regulators in insulin resistance. Folia Med 2013; 55: 25-32.

24. Mrozikiewicz-Rakowska B. Otyłość - induktorem stanu zapalnego. Nowa Klin 2008; 15: 27-33.

25. Raposo I, Torres T. Psoriasis strikes back! Epicardial adipose tissue: another contributor to the higher cardiovascular risk in psoriasis. Rev Port Cardiol 2015; 34: 613-6.

26. Carrascosa JM, Rocamora V, Fernandez-Torres RM, et al. Obesity and psoriasis: inflammatory nature of obesity, relationship between psoriasis and obesity, and therapeutic implications. Actas Dermosifiliogr 2014; 105: 31-44.

27. Davidovici BB, Sattar N, Jörg PC, et al. Psoriasis and systemic inflammatory disease: potential mechanistic links between skin disease and co-morbid conditions. J Invest Dermatol 2010; 130: 1785-96.

28. Marseglia L, Manti S, D’Angelo G, et al. Oxidative stress in obesity: a critical component in human diseases. Int J Mol Sci 2014; 16: 378-400.

29. Nagase M, Yoshida S, Shibata S, et al. Enhanced aldosterone signaling in the early nephropathy of rats with metabolic syndrome: possible contribution of fat-derived factors. I Am Soc Nephrol 2006; 17: 3438-46.

30. Gustafson B. Adipose tissue, inflammation and atherosclerosis. J Atheroscler Thromb 2010; 17: 332-41.

31. Olszanecka-Glinianowicz M, Zahorska-Markiewicz B, Żurakowski A, et al. Rola czynnika martwicy nowotworów (TNF-alfa) w kontroli metabolizmu. Wiad Lek 2005; 58: 670-4.

32. Gerdes S, Rostami-Yazdi M, Mrowietz U. Adipokines and psoriasis. Exp Dermatol 2011; 20: 81-7.

33. Ouchi N, Parker JL, Lugus JJ, et al. Adipokines in inflammation and metabolic disease. Nat Rev Immunol 2011; 11: 85-97.

34. Ismail SA, Mohamed SA. Serum levels of visfatin and omentin-1 in patients with psoriasis and their relation to disease severity. Br J Dermatol 2012; 167: 436-9. 
35. Takahashi H, Tsuji H, Honma M, et al. Increased plasma resistin and decreased omentin levels in Japanese patients with psoriasis. Arch Dermatol Res 2013; 305: 113-6.

36. Gisondi P, Lora V, Bonauguri C, et al. Serum chemerin is increased in patients with chronic plaque psoriasis and normalizes following treatment with infliximab. Br J Dermatol 2013; 168: 749-55.

37. Albanesi C, Scarponi C, Pallota S, et al. Chemerin expression marks early psoriatic skin lesion and correlates with plasmacytoid dendritic cell recruitment. J Exp Med 2008; 206: 249-58.

38. Slominski AT, Zmijewski MA, Skobowiat C, et al. Sensing the environment: regulation of local and global homeostasis by the skin's neuroendocrine system. Adv Anat Embryol Cell Biol 2012; 212: 1-115.

39. Slominski RM, Tuckey RC, Manna PR, et al. Extra-adrenal glucocorticoid biosynthesis: implications for autoimmune and inflammatory disorders. Genes Immun 2020; 21: 150-68.

40. Collins S. Beta-adrenoceptor signaling networks in adipocytes for recruiting stored fat and energy expenditure. Front Endocrinol 2012; 2: 102.

41. Balci A, Balci DD, Yonden Z, et al. Increased amount of visceral fat in patients with psoriasis contributes to metabolic syndrome. Dermatology 2010; 220: 32-7.

42. Ahmed M, Gaffen SL. IL-17 inhibits adipogenesis in part via C/EBP $\alpha$, PPAR $\gamma$ and Krüppel-like factors. Cytokine 2013; 61: 898-905.

43. Winer S, Paltser G, Chan Y, et al. Obesity predisposes to Th17 bias. Eur J Immunol 2009; 39: 2629-35.

44. Gislette T, Chen J. The possible role of IL-17 in obesity-associated cancer. Sci World J 2010; 10: 2265-71.

45. Shin JH, Shin DW, Noh M. Interleukin-17A inhibits adipocyte differentiation in human mesenchymal stem cells and regulates pro-inflammatory responses in adipocytes. Biochem Pharmacol 2009; 77: 1835-44.

46. Sumarac-Dumanovic M, Stevanovic D, Ljubic A, et al. Increased activity of interleukin-23/interleukin-17 proinflammatory axis in obese women. Int J Obese 2009; 33: 151-6.

47. Varshney P, Narasimhan A, Mittal S, et al. Transcriptome profiling unveils the role of cholesterol in IL-17A signaling in psoriasis. Sci Rep 2016; 6: 19295.

48. Jung SH, Park HS, Kim KS, et al. Effect of weight loss on some serum cytokines in human obesity: increase in IL-10 after weight loss. J Nutr Biochem 2008; 19: 371-5.

49. Cozlea DL, Farcas DM, Nagy A, et al. The impact of C reactive protein on global cardiovascular risk on patients with coronary artery disease. Curr Health Sci J 2013; 39: 225-31.

50. Deubelbeiss C, Kolios AGA, Anzengruber F et al. TNF-alpha and IL-17A are differentially expressed in psoriasis-like vs eczema-like drug reactions to TNFalpha antagonists. J Cutan Pathol 2018; 45: 23-8.

51. Guérard S, Pouliot R. The role of angiogenesis in the pathogenesis of psoriasis: mechanisms and clinical implications. J Clin Exp Dermatol Res 2012; S: 2.

52. Hendriks AG, Steenbergen W, Hondebrink E, et al. Whole field laser Doppler imaging of the microcirculation in psoriasis and clinically unaffected skin. J Dermatolog Treat 2014; 25: 18-21.

53. Malecic N, Young HS. Excessive angiogenesis associated with psoriasis as a cause for cardiovascular ischaemia. Exp Dermatol 2017; 26: 299-304.

54. Teixeira GG, Mari NL, de Paula JCC, et al. Cell adhesion molecules, plasminogen activator inhibitor type 1 , and metabolic syndrome in patients with psoriasis. Clin Exp Med 2020; 20: 39-48.

55. Deng W, Feng X, Li X, et al. Hypoxia-inducible factor 1 in autoimmune diseases. Cell Immunol 2016; 303: 7-15.

56. Amin M, Lee EB, Tsai TF, et al. Psoriasis and co-morbidity. Acta Derm Venereol 2020; 100: adv00033.

57. Armstrong EJ, Harskamp CT, Armstrong AW. Psoriasis and major adverse cardiovascular events: a systematic review and meta-analysis of observational studies. J Am Heart Assoc 2013; 2: e000062.

58. Gelfand JM, Dommasch ED, Shin DB, et al. The risk of stroke in patients with psoriasis. J Invest Dermatol 2009; 129: 2411-8.

59. Shiba M, Kato T, Funasako M, et al. Association between psoriasis vulgaris and coronary heart disease in a hospitalbased population in Japan. PLoS One 2016; 11: e0149316.

60. Yim KM, Armstrong AW. Updates on cardiovascular comorbidities associated with psoriatic diseases: epidemiology and mechanisms. Rheumatol Int 2017; 37: 97-105.

61. Hu SC, Lan CE. Psoriasis and cardiovascular comorbidities: focusing on severe vascular events, cardiovascular risk factors and implications for treatment. Int J Mol Sci 2017; 18: E2211.

62. Lai YC, Yew YW. Psoriasis as an independent risk factor for cardiovascular disease: an epidemiologic analysis using a national database. J Cutan Med Surg 2016; 20: 327-33.

63. Wu JJ, Choi YM, Bebchuk JD. Risk of myocardial infarction in psoriasis patients: a retrospective cohort study. J Dermatolog Treat 2015; 26: 230-4.

64. Xian D, Song J, Yang L, et al. Emerging roles of redox-mediated angiogenesis and oxidative stress in dermatoses. Oxid Med Cell Longev 2019; 2019: 2304018.

65. Elsheikh RG, Amin Tel-S, El-Ashmawy AA, et al. Evaluation of subclinical atherosclerosis in Egyptian psoriatic patients. J Saudi Heart Assoc 2014; 26: 63-71.

66. Enany B, El Zohiery AK, Elhilaly R, et al. Carotid intima-media thickness and serum leptin in psoriasis. Herz 2012; 37: 527-33.

67. Ergun T, Yazici V, Yavuz D, et al. Advanced glycation end products, a potential link between psoriasis and cardiovascular disease: a case-control study. Indian J Dermatol 2019; 64: 201-6.

68. Gonzalez-Cantero A, Gonzalez-Cantero J, Sanchez-Moya AI, et al. Subclinical atherosclerosis in psoriasis. Usefulness of femoral artery ultrasound for the diagnosis, and analysis of its relationship with insulin resistance. PLoS One 2019; 14: e0211808.

69. Haberka M, Bańska-Kisiel K, Bergler-Czop B, et al. Mild to moderate psoriasis is associated with oxidative stress, subclinical atherosclerosis, and endothelial dysfunction. Pol Arch Intern Med 2018; 128: 434-9.

70. Fang N, Jiang M, Fan Y. Association between psoriasis and subclinical atherosclerosis: a meta-analysis. Medicine 2016; 95: e3576.

71. Batycka-Baran A, Paprocka M, Krawczenko A, et al. Reduced number of circulating endothelial progenitor cells (CD133+/ $\mathrm{KDR}+$ ) in patients with plaque psoriasis. Dermatology 2012; 225: 88-92.

72. Batycka-Baran A, Paprocka M, Krawczenko A, et al. Increased number of circulating endothelial cells (CECS) in patients with psoriasis - preliminary report. J Eur Acad Dermatol Venereol 2014; 28: 116-9.

73. Perk J, De Backer G, Gohlke H, et al. European Guidelines on cardiovascular disease prevention in clinical practice (version 2012): The Fifth Joint Task Force of the European Society of Cardiology and Other Societies on Cardiovascular Disease 
Prevention in Clinical Practice (constituted by representatives of nine societies and by invited experts). Atherosclerosis 2012; 223: 1-68.

74. Yan D, Afifi L, Jeon C, et al. The metabolomics of psoriatic disease. Psoriasis 2017; 7: 1-15.

75. Jiang S, Hinchliffe TE, Wu T. Biomarkers of an autoimmune skin disease - psoriasis. Genomics Proteomics Bioinformatics 2015; 13: 224-33.

76. Aggarwal D, Arumalia N, Jethwa H, et al. The use of biomarkers as a tool for novel psoriatic disease drug discovery. Expert Opin Drug Discov 2018; 13: 1-13.

77. Chularojanamontri L, Charoenpipatsin N, Silpa-Archa N, et al. Proteomics in Psoriasis. Int J Mol Sci 2019; 20: 1141.

78. Butt AQ, McArdle A, Gibson DS, et al. Psoriatic arthritis under a proteomic spotlight: application of novel technologies to advance diagnosis and management. Curr Rheumatol Rep 2015; 17: 35 .

79. Lamoureux F, Mestre E, Essig M, et al. Quantitative proteomic analysis of cyclosporine-induced toxicity in a human kidney cell line and comparison with tacrolimus. J Proteom 2011; 75: 677-94.

80. van Swelm RP, Laarakkers CM, Kooijmans-Otero M, et al. Biomarkers for methotrexate-induced liver injury: urinary protein profiling of psoriasis patients. Toxicol Lett 2013; 221: 219-24.

81. Trowbridge RM, Pittelkow MR. Epigenetics in the pathogenesis and pathophysiology of psoriasis vulgaris. J Drugs Dermatol 2014; 13: 111-8.

82. Alehagen $U$, Johansson $P$, Aaseth J, et al. Significant changes in circulating microRNA by dietary supplementation of selenium and coenzyme Q10 in healthy elderly males. A subgroup analysis of a prospective randomized doubleblind placebo-controlled trial among elderly Swedish citizens. PLoS One 2017; 12: e0174880.

83. Kharaeva Z, Gostova E, De Luca C, et al. Clinical and biochemical effects of coenzyme Q(10), vitamin $E$, and selenium supplementation to psoriasis patients. Nutrition 2009; 25: 295-302.

84. Boele J, Persson H, Shin JW, et al. PAPD5-mediated 3' adenylation and subsequent degradation of miR-21 is disrupted in proliferative disease. Proc Natl Acad Sci USA 2014; 111 11467-72.

85. Kocic H, Damiani, G, Stamenkovic, B, et al. Dietary compounds as potential modulators of microRNA expression in psoriasis. Therap Adv Chr Dis 2019; 10: 2040622319864805.

86. Guinea-Viniegra J, Jiménez M, Schonthaler HB, et al. Targeting miR-21 to treat psoriasis. Sci Transl Med 2014; 6: 225re1.

87. Meisgen F, Xu N, Wei T, et al. MiR-21 is up-regulated in psoriasis and suppresses T cell apoptosis. Exp Dermatol 2012; 21: 312-4.

88. Latruffe N, Lançon A, Frazzi R, et al. Exploring new ways of regulation by resveratrol involving miRNAs, with emphasis on inflammation. Ann N Y Acad Sci 2015; 1348: 97-106.

89. Li H, Jia Z, Li A, et al. Resveratrol repressed viability of U251 cells by miR-21 inhibiting of NF-kappaB pathway. Mol Cell Biochem 2013; 382: 137-43.

90. Tili E, Michaille JJ, Adair B, et al. Resveratrol decreases the levels of miR-155 by upregulating miR-663, a microRNA targeting JunB and JunD. Carcinogenesis 2010; 31: 1561-6.

91. Boesch-Saadatmandi C, Loboda A, Wagner AE, et al. Effect of quercetin and its metabolites isorhamnetin and quercetin-3-glucuronide on inflammatory gene expression: role of miR-155. J Nutr Biochem 2011; 22: 293-9.
92. Karkeni E, Bonnet L, Marcotorchino J, et al. Vitamin D limits inflammation-linked microRNA expression in adipocytes in vitro and in vivo: a new mechanism for the regulation of inflammation by vitamin D. Epigenetics 2018; 13: 156-62.

93. Kempinska-Podhorodecka A, Milkiewicz M, Wasik U, et al. Decreased expression of vitamin D receptor affects an immune response in primary biliary cholangitis via the VDRmiRNA155-SOCS1 pathway. Int J Mol Sci 2017; 18: pii: E289.

94. Giangreco AA, Vaishnav A, Wagner D, et al. Tumor suppressor microRNAs, miR-100 and $-125 b$, are regulated by 1,25-dihydroxyvitamin D in primary prostate cells and in patient tissue. Cancer Prev Res (Phila) 2013; 6: 483-94.

95. Boesch-Saadatmandi C, Wagner AE, Wolffram S, et al. Effect of quercetin on inflammatory gene expression in mice liver in vivo - role of redox factor 1 , miRNA-122 and miRNA125b. Pharmacol Res 2012; 65: 523-30.

96. Owczarczyk-Saczonek A, Placek W. Dieta w łuszczycy. [In:] Dieta w chorobach skóry. Placek W (ed.). Czelej, Lublin 2015.

97. Bridgman AC, Qureshi AA, Li T, et al. Inflammatory dietary pattern and incident psoriasis, psoriatic arthritis, and atopic dermatitis in women: a cohort study. J Am Acad Dermatol 2019; 80: 1682-90.

98. Owczarczyk-Saczonek A, Lahuta LB, Placek W, et al. The potential benefits of plant cyclitols in the treatment of psoriasis. Pol Ann Medic 2018; 25: 1.

99. Johnson JA, Ma C, Kanada KN, et al. Diet and nutrition in psoriasis: analysis of the National Health and Nutrition Examination Survey (NHANES) in the United States. J Eur Acad Dermatol Venereol 2014; 28: 327-32.

100. Tabung FK, Smith-Warner SA, Chavarro JE, et al. Development and validation of an empirical index of dietary inflammatory potential. J Nutr 2016; 146: 1560-70.

101. Herbert D, Franz S, Popkova Y, et al. High-Fat diet exacerbates early psoriatic skin inflammation independent of obesity: saturated fatty acids as key players. J Invest Dermatol 2018; 138: 1999-2009.

102. Owczarczyk-Saczonek A, Lahuta LB, Ligor M, et al. The healing-promoting properties of selected cyclitols - a review. Nutrients 2018; 10: 1891.

103. Wolters M. Diet and psoriasis: experimental data and clinical evidence. Br J Dermatol 2005; 153: 706-14.

104. Yazici C, Köse K, Utaş S, et al. A novel approach in psoriasis: first usage of known protein oxidation markers to prove oxidative stress. Arch Dermatol Res 2016; 308: 207-12.

105. Lin X, Huang T. Oxidative stress in psoriasis and potential therapeutic use of antioxidants. Free Radic Res 2016; 50: 585-95.

106. Adawi M, Damiani G, Bragazzi NL, et al. The impact of intermittent fasting (Ramadan Fasting) on psoriatic arthritis disease activity, enthesitis, and dactylitis: a multicentre study. Nutrients 2019; 11: 601.

107. Chamcheu JC, Pal HC, Siddiqui IA, et al. Prodifferentiation, anti-inflammatory and antiproliferative effects of delphinidin, a dietary anthocyanidin, in a full-thickness threedimensional reconstituted human skin model of psoriasis. Skin Pharmacol Physiol 2015; 28: 177-88.

108. Simopoulos AP. An increase in the omega-6/omega-3 fatty acid ratio increases the risk for obesity. Nutrients 2016; 8: 128.

109. Zehr KR, Walker MK. Omega-3 polyunsaturated fatty acids improve endothelial function in humans at risk for atherosclerosis: a review. Prostaglandins Other Lipid Mediat 2018; 134: 131-40. 
110. Calder PC. Omega-3 polyunsaturated fatty acids and inflammatory processes: nutrition or pharmacology? Br J Clin Pharmacol 2013; 75: 645-62.

111. Upala S, Yong WC, Theparee T, et al. Effect of omega-3 fatty acids on disease severity in patients with psoriasis: a systematic review. Int J Rheum Dis 2017; 20: 442-50.

112. Yang CY, Leung PS, Adamopoulos IE, et al. The implication of vitamin D and autoimmunity: a comprehensive review. Clin Rev Allergy Immunol 2013; 45: 217-26.

113. Barrea L, Savanelli MC, Di Somma C, et al. Vitamin D and its role in psoriasis: an overview of the dermatologist and nutritionist. Rev Endocr Metab Disord 2017; 18: 195-205.

114. Barrea L, Balato N, Di Somma C, et al. Nutrition and psoriasis: is there any association between the severity of the disease and adherence to the Mediterranean diet? J Transl Med 2015; 13: 18.

115. Gisondi P, Rossini M, Di Cesare A, et al. Vitamin D status in patients with chronic plaque psoriasis. Br J Dermatol 2012; 166: 505-10.

116. Mattozzi C, Paolino G, Salvi M, et al. Peripheral blood regulatory $T$ cell measurements correlate with serum vitamin $\mathrm{D}$ level in patients with psoriasis. Eur Rev Med Pharmacol Sci 2016; 20: 1675-9.

117. Ricceri F, Pescitelli L, Tripo L, et al. Deficiency of serum concentration of 25-hydroxyvitamin D correlates with severity of disease in chronic plaque psoriasis. J Am Acad Dermatol 2013; 68: 511-2.

118. Fukuya Y, Higaki M, Higaki Y, et al. Effect of vitamin D3 on the increased expression of $\mathrm{Bcl}-\mathrm{xL}$ in psoriasis. Arch Dermatol Res 2002; 293: 620-5.

119. Slominski AT, Li W, Kim TK, et al. Novel activities of CYP11A1 and their potential physiological significance. J Steroid Biochem Mol Biol 2015; 151: 25-37.

120. Slominski AT, Kim TK, Janjetovic Z, et al. Differential and overlapping effects of 20,23(OH)(2)D3 and 1,25(OH)(2) D3 on gene expression in human epidermal keratinocytes: identification of AhR as an alternative receptor for 20,23(OH)(2)D3. Int J Mol Sci 2018; 19: 3072.

121. Jetten AM, Takeda Y, Slominski A, et al. Retinoic acid-related Orphan Receptor gamma (RORgamma): connecting sterol metabolism to regulation of the immune system and autoimmune disease. Curr Opin Toxicol 2018; 8: 66-80.

122. Janjetovic Z, Tuckey RC, Nguyen MN, et al. 20,23-dihydroxyvitamin D3, novel P450scc product, stimulates differentiation and inhibits proliferation and NF-kappaB activity in human keratinocytes. J Cell Physiol 2010; 223: 36-48.

123. Phan C, Touvier M, Kesse-Guyot E, et al. Association between mediterranean anti-inflammatory dietary profile and severity of psoriasis: results from the NutriNet-Santé cohort. JAMA Dermatol 2018; 154: 1017-24.

124. Bach-Faig A, Berry EM, Lairon D, et al. Mediterranean Diet Foundation Expert Group. Mediterranean diet pyramid today: science and cultural updates. Public Health Nutr 2011; 14: 2274-84.

125. Zuccotti E, Oliveri M, Girometta C, et al. Nutritional strategies for psoriasis: current scientific evidence in clinical trials. Eur Rev Med Pharmacol Sci 2018; 22: 8537-51.

126. Afifi L, Danesh MJ, Lee KM, et al. Dietary behaviors in psoriasis: patient-reported outcomes from a U. S. National Survey. Dermatol Ther (Heidelb) 2017; 7: 235-6.

127. Ford AR, Siegel M, Bagel J, et al. Dietary recommendations or adults with psoriasis or psoriatic arthritis from the Medical Board of the National Psoriasis Foundation: a systematic review. JAMA Dermatol 2018; 154: 934-50.
128. Bhatia BK, Millsop JW, Debbaneh M, et al. Diet and psoriasis, part II: celiac disease and role of a gluten-free diet. J Am Acad Dermatol 2014; 71: 350-8.

129. Setty AR, Curhan G, Choi HK. Obesity, waist circumference, weight change, and the risk of psoriasis in women: Nurses' Health Study II. Arch Intern Med 2007; 167: 1670-5.

130. Millsop JW, Bhatia BK, Debbaneh M, et al. Diet and psoriasis, part III: role of nutritional supplements. J Am Acad Dermatol 2014; 71: 561-9.

131. Stehlikova Z, Kostovcikova K, Kverka M, et al. Crucial role of microbiota in experimental psoriasis revealed by a gnotobiotic mouse model. Front Microbiol 2019; 10: 236.

132. Yousefzadeh H, Jabbari Azad F, Banihashemi M, et al. Evaluation of psoriasis severity and inflammatory responses under concomitant treatment with methotrexate plus micronutrients for psoriasis vulgaris: a randomized double blind trial. Acta Dermatovenerol Alp Pannonica Adriat 2017; 26: 3-9.

133. Corbetta S, Angioni R, Cattaneo A, et. Effects of retinoid therapy on insulin sensitivity, lipid profile and circulating adipocytokines. Eur J Endocrinol 2006; 154: 83-6. 